\section{Effect of Breast Cancer Treatment on the Stomatognathic System}

Danilo Stefani Esposto1, Marcelo Palinkas², Ligia Maria Napolitano Gonçalves $^{3}$, Paulo Batista de Vasconcelos², Vânia Tie Koga Ferreira ${ }^{4}$, Elaine Caldeira de Oliveira Guirro ${ }^{1}$, Selma Siéssere ${ }^{2}$, Simone Cecilio Hallak Regalo ${ }^{2}$
'Department of Biomechanics, Medicine and Locomotive Apparatus Rehabilitation, Ribeirão Preto Medical School, USP- Universidade de São Paulo, Ribeirão Preto, SP, Brazil 2Department Morphology, Physiology and Basic Pathology, School of Dentistry of Ribeirão Preto, USP - Universidade de São Paulo, Ribeirão Preto, SP, Brazil ${ }^{3}$ Department of Restorative Dentistry, School of Dentistry of Ribeirão Preto, USP - Universidade de São Paulo, Ribeirão Preto, SP, Brazil ${ }^{4}$ Department of Health Sciencs, UNIFAP - Universidade Federal do Amapá, Macapá, AP, Brazil

Correspondence: Marcelo Palinkas, Avenida do Café, s/n, 14040-904 Ribeirão Preto, SP, Brasil. Tel: +55-163315-3000. e-mail: palinkas@usp.br

Key Words: Breast, cancer, mastectomy, masticatory muscles.

\section{Introduction}

Breast cancer is a global public health problem with the highest survival rates, around 80\%, among all cancers, when diagnosed early (1). In 2016, it was estimated the incidence of 246660000 cases, with 40450 deaths in the United States (2) and 57960 new cases in Brazil (3). Mortality rates are high, because the disease is still diagnosed in advanced stages, despite being considered a type of cancer with positive prognosis.

The surgical procedure is the most used approach in the treatment of breast cancer, comprising the conservative and non-conservative modality that encompasses total breast resection, called mastectomy (4).

Physical limitations are reported as a result of breast cancer treatment (5), as well as oral physiology alterations (6) and psychological changes, especially when it is related to anxiety and self-esteem (7).

With the evolution of the surgical techniques and the increasing incidence of malignant neoplasm in the breast, is necessary to verify the postoperative functional alterations resulting from the current procedures (8), because many mastectomized women present changes in the body posture, asymmetries in the trunk, limited range of motion on upper limbs and muscle disorders $(9,10)$.

The neck muscles are essential for maintaining cervical balance and of masticatory muscles, where surgical interventions may result in functional alterations of this system (11).

Thus, the importance of this study to provide information that can guide the process of evaluation and clinical follow-up of the mastectomized women, presenting a clarifying character for health professionals with the purpose of contributing to the functional analysis of the stomatognathic system.

Therefore, the objective of this unprecedented study was to evaluate the stomatognathic system function of women underwent unilateral mastectomy, by electromyographic activity, masticatory efficiency, muscle thickness and maximum molar bite force.

The hypothesis of this study is that unilateral mastectomy in women could present dysfunction in the stomatognathic system, as an increase in electromyographic activity of masticatory muscles, reduction in masticatory efficiency and lower maximum molar bite force.

\section{Material and Methods Ethical Approval}

The data were collected in the region of Ribeirão Preto, São Paulo, Brazil. The research was approved by the Research 
Ethics Committee of the School of Dentistry of Ribeirão Preto, São Paulo, Brazil (process n. 38290714.8.0000.5381). All participants signed the informed consent form in accordance with Resolution 466/12 and the Complementary of the National Health Council.

\section{Participants}

The sample size was calculated by maximum significance level of $\alpha=0.05$ and minimum power of $80 \%$ in the test, assuming a sample loss of $30 \%$, and it was possible to determine $n=16$ individuals for each group studied (case and control). For the sample calculation was used the difference of twice the standard deviation of all the variables evaluated and was considered the one that presented the largest sample size.

A total of 40 women were selected to participate in the study, of which 8 were excluded because they presented previous orthopedic alterations of the cervical region and upper limbs $(n=2)$; cognitive alterations $(n=1)$; previous trauma in the head and neck region $(n=1)$; small breasts (12) $(n=2)$ and lymphedema in the upper limbs (13) $(n=2)$.

In this way, 32 women with normal occlusion, without temporomandibular dysfunction (RDC/TMD) and orofacial pain were distributed in two groups: unilateral mastectomy group (MG), average \pm standard deviation $56.50 \pm 14.50$ years $(n=16)$, and without the disease group (CG), average \pm standard deviation $56.56 \pm 14.15$ years $(n=16)$. The groups were matched individual-to-individual by age and anthropometric measures (Table 1).

The complementary characteristics of the unilateral mastectomized women were: without presence of metastasis $(n=16)$, surgery time greater than 12 months $(n=14)$, use of breast prosthesis after mastectomy $(n=14)$, surgical side (right, $n=9$ and left, $n=7$ ), chemotherapy treatment $(n=11)$, radiotherapeutic treatment $(n=9)$, hormone therapy $(n=3)$ and level of active physical activity assessed by the International Physical Activity Questionnaire ( $n=9)(14)$.

\section{Electromyographic Analysis}

The electromyographic signals were collected by the Trigno electromyographer (Delsys Inc., Boston, MA, USA) with wireless surface electrodes. The positioning of the electrodes on the temporalis and masseter muscle was identified by the use of the maximum voluntary contraction maneuver.

Prior to the placement of the electrodes, the skin was cleaned with alcohol to remove any residues of fat, make-up or pollution. During the electromyographic recording, the environment was kept calm, with the participants sitting in a comfortable chair, feet resting on the ground, with an upright posture and hands resting on the thighs. The head was erected, keeping the horizontal plane of Frankfurt parallel to the ground.

The evaluation of electromyographic activity was performed during mandibular rest (4s), right laterality (10s), left laterality (10 s), protrusion (10 s) and dental clenching in maximal voluntary contraction with (4s) and without Parafilm (4s). The Parafilm consisted of a folded paraffin sheet (Parafilm Mâ, Pechiney Plastic Packaging, Batavia, IL, USA) (18x17x4mm, weight $245 \mathrm{mg})$ and placed between the occlusal faces of the first and second molars on the dental arch right and left sides.

The efficiency of the masticatory cycles in habitual and non-habitual chewing was analyzed by the integral of the linear envelope average of the electromyographic signal for both, temporalis and masseter muscles. Chewing with peanuts, simulating consistent food and raisins without seeds simulating soft food was used for the habitual mastication and for non-habitual chewing the Parafilm was used $(15,16)$. The food belonged to the same manufacturing batch and was stored in individualized plastic bowls with lid, kept in a cool and airy environment.

The electromyographic signals were processed by Delsys electromyographic works analysis software, version 4 . The values of the envelopment integral of the masticatory cycles in usual and non-habitual were obtained, eliminating the first three first cycles of the masticatory process and analyzing the five central cycles. The initial masticatory cycles were neglected, considering that, at the beginning of the masticatory process, there is considerable variation in the pattern of mandibular movement.

\section{Muscle Thickness Analysis}

The Sonosite Titan system portable ultrasound device with linear transducer was used to analyze the thickness of the temporalis and masseter muscles by recording ultrasound images under tasks of mandibular rest and dental clenching in maximum voluntary contraction.

The linear transducer was positioned transversely towards the fibers of the assessed muscles, coupled to the surface of the skin with a water-based electrically conductive gel. In the anterior portion of the temporalis muscle, the transducer was positioned in the region of the temporal fossa about 1.0 to $1.5 \mathrm{~cm}$ behind and above the outer angle of the eye. For the muscle belly of the masseter muscle, the linear transducer was positioned approximately 1.5 to $2.0 \mathrm{~cm}$ above the angle of the mandible toward the zygomatic arch.

For each mandibular task, three exams with a twominute interval between them were performed, being considered the average value between the three measures.

\section{Bite Force Analysis}

The digital dynamometer (IDDK, Kratos, Cotia, SP, Brazil) 
was used, adapted for buccal conditions with a capacity of up to $980.665 \mathrm{~N}$ to obtain the records of the maximum molar bite force, according to the laboratory protocol.

The participants were placed in a comfortable chair with their feet resting on the ground, standing upright and their hands resting on their thighs. For biosecurity reasons, the stems of the dynamometer were cleaned with alcohol, protected with disposable latex finger cots (Wariper, São Paulo, SP, Brazil) and positioned in the region of the first right and left first molar, where the greatest bite force is developed.

The participants tightened three times with maximum force the dynamometer rods, interspersing right and left side, with a two minutes rest between each record. It was considered the largest bite force on both sides.

\section{Statistical Analysis}

Due to the need for comparisons between different participants, the values of RMS and integral of the linear envelope of the electromyographic signal obtained during the maximal voluntary contraction with Parafilm were used to normalize the electromyographic activity values. Normalized electromyographic data in microvolts/second (rest, right and left laterality, protrusion, dental clenching in maximal voluntary contraction with and without Parafilm, chewing with peanuts, raisins and Parafilm), ultrasound data in centimeters (rest and dental clenching in maximum voluntary contraction) and maximal molar bite force data in newtons (right and left) were submitted to statistical analysis using the Statistical Package for Social Sciences (SPSS version 21.0, IBM ${ }^{\circledR}$, USA). Descriptive analysis (mean and standard error) and Shapiro-Wilk normality test were used for each variable. The values were compared by Student's $t$ test for independent samples $(p \leq 0.05)$.

\section{Results}

Average age and anthropometric measurements data of $M G$ and $C G$ are shown in Table 1. There was no statistically significant difference $(p \leq 0.05)$ for these variables between the groups. Table 2 shows the average thickness of the temporal and masseters muscles at rest and maximum voluntary contraction between MG and CG. There was

Table 1. Comparison of means of the anthropometric measurements [weight $(\mathrm{Kg})$ and height $(\mathrm{cm})$ ] and age (years) between mastectomy group (MG) and without the disease group $(\mathrm{GC})$ using $t$ test $(\mathrm{p} \leq 0.05)$

\begin{tabular}{lccc} 
& MG & CG & p value \\
\hline Age & $56.50 \pm 14.50$ & $56.56 \pm 14.15$ & 0.99 \\
Weight & $65.59 \pm 7.53$ & $66.37 \pm 9.54$ & 0.79 \\
Height & $1.60 \pm 0.06$ & $1.62 \pm 0.04$ & 0.54 \\
\hline
\end{tabular}

no statistically significant difference $(p \leq 0.05)$ between the groups.

The normalized electromyographic data of the temporal and masseter muscles during rest and mandibular postural tasks for MG and $C G$ are presented in Table 3. Significant statistical differences $(p \leq 0.05)$, between $M G$ and $C G$, were observed in the right laterality (right masseter) and left laterality (left masseter). The MG presented higher electromyographic activity under mandibular task, except for right laterality (left temporal) and maximum voluntary contraction with Parafilm (right temporal and left masseter).

Table 4 indicates the average of habitual and nonhabitual masticatory efficiency for $M G$ and $C G$. Significant statistical difference $(p \leq 0.05)$, between $M G$ and $C G$, was observed during peanut chewing (right masseter). The MG showed greater electromyographic activity in the dynamic tasks of the mandible.

The average molar bite force values of the right and left sides are shown in Table 5. There was a significant statistical difference $(p \leq 0.05)$, between $M G$ and $C G$, in the right bite force, with lower force for MG.

\section{Discussion}

The rehabilitation of the breast after removal of cancer can create organic complications that hinder the muscular function, promoting spasms and sensitivity (17).

The stomatognathic system, because it is complex, present's well-defined physiological functions, requiring mandible requisition, associated with the movements of

Table 2. Averages means, standard errors $( \pm)$ and statistical significance $(\mathrm{p} \leq 0.05)$ of the thickness of the right masseter (RM), left masseter (LM), right temporal (RT) and left temporal (LT) during rest and dental clenching in mastectomy group (MG) and without the disease group (CG)

\begin{tabular}{lccc}
\hline $\begin{array}{l}\text { Mandibular task } \\
\text { and muscles }\end{array}$ & MG & CG & p value \\
\hline Rest & & & \\
RT & $0.30 \pm 0.01$ & $0.33 \pm 0.04$ & 0.56 \\
LT & $0.29 \pm 0.01$ & $0.28 \pm 0.01$ & 0.44 \\
RM & $0.86 \pm 0.04$ & $0.86 \pm 0.02$ & 0.92 \\
LM & $0.84 \pm 0.02$ & $0.83 \pm 0.03$ & 0.81 \\
Dental Clenching & & & \\
RT & & & \\
LT & $0.41 \pm 0.03$ & $0.44 \pm 0.04$ & 0.50 \\
RM & $0.41 \pm 0.02$ & $0.41 \pm 0.02$ & 0.82 \\
LM & $1.05 \pm 0.04$ & $1.08 \pm 0.03$ & 0.51 \\
\hline
\end{tabular}


structures of the face and neck (18). If a disease occurs in the human body, this system will use adaptive resources to maintain functional efficiency so as not to allow failures to occur, which may be manifested by signs and symptoms of dysfunction (19).

The study of the mechanisms of development and the functions of this complex system can provide parameters useful in the recognition of deviations from normality. Therefore, the objective of this study was to determine if women submitted to unilateral mastectomy would present functional alterations in the stomatognathic system.

We observed that in the mandibular rest, the temporalis and masseter muscles presented electromyographic activity in both groups, however in $\mathrm{MG}$, the activity was greater.

Table 3. Means, standard errors $( \pm)$ and statistical significance $(p \leq 0.05)$ of the normalized electromyographic data $(\mu \mathrm{V})$ averages of the right masseter (RM), left masseter (LM), right temporal (RT) and left temporal (LT) for mastectomy group (MG) and without the disease group (CG) in the mandibular task

\begin{tabular}{|c|c|c|c|c|}
\hline $\begin{array}{l}\text { Mandibular } \\
\text { Task }\end{array}$ & Muscles & MG & CG & $\mathrm{p}$ value \\
\hline \multirow{4}{*}{ Rest } & RT & $0.16 \pm 0.03$ & $0.11 \pm 0.02$ & 0.12 \\
\hline & LT & $0.15 \pm 0.04$ & $0.10 \pm 0.02$ & 0.24 \\
\hline & RM & $0.08 \pm 0.01$ & $0.07 \pm 0.01$ & 0.51 \\
\hline & LM & $0.10 \pm 0.02$ & $0.08 \pm 0.02$ & 0.44 \\
\hline \multirow{4}{*}{ Right laterality } & RT & $0.32 \pm 0.11$ & $0.13 \pm 0.02$ & 0.10 \\
\hline & LT & $0.10 \pm 0.02$ & $0.10 \pm 0.01$ & 0.96 \\
\hline & RM & $0.27 \pm 0.07$ & $0.08 \pm 0.01$ & 0.02 \\
\hline & LM & $0.23 \pm 0.05$ & $0.14 \pm 0.03$ & 0.12 \\
\hline \multirow{4}{*}{ Left laterality } & RT & $0.15 \pm 0.03$ & $0.10 \pm 0.02$ & 0.11 \\
\hline & LT & $0.20 \pm 0.05$ & $0.12 \pm 0.02$ & 0.14 \\
\hline & RM & $0.17 \pm 0.03$ & $0.10 \pm 0.02$ & 0.07 \\
\hline & LM & $0.23 \pm 0.05$ & $0.09 \pm 0.02$ & 0.01 \\
\hline \multirow{4}{*}{ Protrusion } & RT & $0.18 \pm 0.03$ & $0.13 \pm 0.02$ & 0.20 \\
\hline & LT & $0.12 \pm 0.02$ & $0.09 \pm 0.01$ & 0.16 \\
\hline & RM & $0.25 \pm 0.06$ & $0.14 \pm 0.03$ & 0.13 \\
\hline & LM & $0.25 \pm 0.04$ & $0.17 \pm 0.04$ & 0.17 \\
\hline \multirow{4}{*}{$\begin{array}{l}\text { Dental } \\
\text { clenching with } \\
\text { Parafilm } \mathrm{M}^{\circledast}\end{array}$} & RT & $0.67 \pm 0.09$ & $0.73 \pm 0.09$ & 0.67 \\
\hline & LT & $0.72 \pm 0.09$ & $0.71 \pm 0.10$ & 0.95 \\
\hline & RM & $0.73 \pm 0.09$ & $0.64 \pm 0.09$ & 0.50 \\
\hline & LM & $0.60 \pm 0.05$ & $0.64 \pm 0.11$ & 0.77 \\
\hline
\end{tabular}

The masticatory, cervical and thoracic musculature present delineated anatomical relationships, with interdependent functions (20) and after invasive treatment in the thoracic region, all postural maintenance may be impaired, promoting muscle imbalance (18), leading to the destabilization of the mandibular positioning, causing functional alteration of the masticatory muscles fibers and consequently muscular hyperactivity (21).

In the protrusion, the activation pattern of the temporalis muscles was greater than that of the masseter in both groups, with a higher normalized electromyographic activity in the MG. These results are in agreement with the pattern described in the literature, where the temporalis muscles are more active than the masseter muscles (22). The mandibular excursion movements are influenced by the position of the head, peripheral impulses and emotional situations (18). After the mastectomy, functional morbidities are observed, highlighting posture changes

Table 4. Means, standard errors $( \pm)$ and statistical significance $(p \leq 0.05)$ of the normalized electromyographic data $(\mu \mathrm{V})$ of the right masseter (RM), left masseter (LM), right temporal (RT) and left temporal (LT) for mastectomy group (MG) and without the disease group (CG) in the mandibular task of habitual chewing (peanuts and raisins) and non-habitual chewing (Parafilm $\mathrm{M}^{\circledR}$

\begin{tabular}{lcccc}
\hline Chewing & Muscles & MG & CG & p value \\
\hline \multirow{4}{*}{ Peanuts } & RT & $0.79 \pm 0.15$ & $0.60 \pm 0.16$ & 0.39 \\
& LT & $0.56 \pm 0.07$ & $0.47 \pm 0.08$ & 0.42 \\
& RM & $0.86 \pm 0.14$ & $0.52 \pm 0.07$ & 0.04 \\
& LM & $0.80 \pm 0.17$ & $0.53 \pm 0.08$ & 0.15 \\
Raisins & RT & $0.57 \pm 0.14$ & $0.53 \pm 0.16$ & 0.83 \\
& LT & $0.48 \pm 0.06$ & $0.41 \pm 0.07$ & 0.47 \\
& RM & $0.65 \pm 0.14$ & $0.45 \pm 0.09$ & 0.26 \\
& LM & $0.70 \pm 0.15$ & $0.35 \pm 0.05$ & 0.04 \\
& & & & \\
Parafilm M & & & & \\
& RT & $0.89 \pm 0.16$ & $0.77 \pm 0.25$ & 0.69 \\
& LT & $0.79 \pm 0.12$ & $0.61 \pm 0.10$ & 0.25 \\
& RM & $0.74 \pm 0.16$ & $0.63 \pm 0.11$ & 0.57 \\
& LM & $0.92 \pm 0.18$ & $0.59 \pm 0.06$ & 0.09 \\
\hline
\end{tabular}

Table 5. Means, standard errors $( \pm)$ and statistical significance ( $\mathrm{p} \leq 0.05)$ of the right and left molar bite force (N) for mastectomy group (MG) and without the disease group (CG)

\begin{tabular}{lccc}
\hline & MG & CG & p value \\
\hline Right molar & $139.84 \pm 19.22$ & $195.15 \pm 14.91$ & 0.03 \\
Left molar & $148.18 \pm 18.53$ & $188.97 \pm 13.34$ & 0.08 \\
\hline
\end{tabular}


that affect the stomatognathic system, mainly in the mandibular kinematics and promoting alterations of the masticatory function (23).

Our findings showed that in the right and left laterality, the activation of the masseter muscles did not follow the appropriate neuroanatomical pattern, demonstrating that the greater muscle contralateral activity during the function was not found. It was observed that in the mandibular excursion movements, the normalized electromyographic activities of the temporalis and masseter muscles were smaller in the MG when compared to the CG. Women undergoing breast cancer treatment present muscle tension, fatigue, and depression (24). These factors may interfere with the impairment of the masticatory function, causing functional alteration (25), however, variables such as tension, fatigue and depression were not evaluated in this study.

In the maximum voluntary contraction task, the left masseter and right temporalis muscles demonstrated lower electromyographic activity in MG compared to CG. The surgical procedure that reconstructs the breast, after the mastectomy, returning the volume and contour, may not restore the natural function of the breast, altering the stable include fifteen participants with medium breasts and one participant with large breasts.

In this study, the masticatory performance was evaluated by the use of food tests such as peanuts, representing the consistent food, raisins reproducing the soft food and the Parafilm as inert material. The use of the inert material had the function of demonstrating the joint play movement of the dynamic records, of buccal opening short excursion, requested to reduce effects of the change of muscular length. It was observed that in the habitual mastication (peanuts and raisins) and non-habitual (Parafilm), MG presented higher normalized electromyographic activity when compared to CG. When muscular hyperactivity is observed in dynamic actions of individuals who have suffered functional alterations, it is noticed that the muscular fibers behave in a different way, being more recruitment to maintain the same performance, when in comparison with healthy system (16). This hypothesis may explain the less efficient results of masticatory performance in mastectomized women.

The parameters related to the thickness of the masticatory muscles and molar bite force, in women submitted to mastectomy was not studied until the present moment of this research. This situation justifies 


\section{Resumo}

Câncer de mama é a neoplasia mais comum que mais acomete mulheres no mundo e proporciona alterações funcionais no corpo humano. Objetivo: avaliar mulheres submetidas à mastectomia unilateral, por meio da atividade eletromiográfica (repouso mandibular, lateralidade direita e esquerda, protrusão, contração voluntária máxima com e sem parafilme, mastigação habitual e não habitual) e espessura (repouso e contração voluntária máxima) do músculo temporal direito (TD), temporal esquerdo (TE), masseter direito (MD) e masseter esquerdo (ME), além da força de mordida molar (direita e esquerda) e comparar os dados com mulheres saudáveis. 32 mulheres foram distribuidas em dois grupos: grupo mastectomia unilateral $(\mathrm{GM})$, média \pm desvio padrão $56,50 \pm$ 14,50 anos $(n=16)$ e grupo sem a doença $(\mathrm{GC})$, média \pm desvio padrão $56,56 \pm 14,15$ anos $(n=16)$. Os dados eletromiográficos normalizados, espessura muscular e força de mordida molar máxima foram tabulados e submetidos à análise estatística (SPSS 21.0; teste t de student, $p \leq 0,05$ ). Foram encontradas diferenças estatísticas significantes entre GM e GC na lateralidade direita, para o MD $(p=0,02)$; lateralidade esquerda, para o TE $(p=0,01)$; mastigação com amendoim, para o $\mathrm{MD}(p=0,04)$; mastigação com uva-passa, para o $\mathrm{ME}(\mathrm{p}=0,04)$ e força de mordida molar direita $(p=0,03)$. Não houve diferença estatística significante entre GM e GC para espessura muscular. Os resultados deste estudo sugerem que mulheres submetidas à mastectomia unilateral podem apresentar alterações funcionais do sistema estomatognático, com destaque para hiperatividade muscular, menor eficiência mastigatória e menor força de mordida molar máxima.

\section{Acknowledgements}

We gratefully acknowledge the support of Coordenação de Aperfeiçoamento de Pessoal de Nivel Superior (CAPES) and National Institute and Technology - Translational Medicine (INCT.TM).

\section{References}

1. Athiyaman $\mathrm{H}$, Athiyaman $\mathrm{M}$, Chougule $\mathrm{A}$, Kumar HS. Estimated Risk of Radiation Induced Contra Lateral Breast Cancer Following Chest Wall Irradiation by Conformal Wedge Field and Forward Intensity Modulated Radiotherapy Technique for Post-Mastectomy Breast Cancer Patients. Asian Pac J Cancer Prev 2016;17:6007-6011.

2. Siegel RL, Miller KD, Jemal A. Cancer statistics, 2016. CA Cancer J Clin 2016;66:7-30.

3. Rocha-Brischiliari SC, Oliveira RR, Andrade L, Brischiliari A, Gravena AA, Carvalho MD, Pelloso SM, et al. The Rise in Mortality from Breast Cancer in Young Women: Trend Analysis in Brazil. PLoS One 2017;12:e0168950.

4. Braude L, Laidsaar-Powell R, Gilchrist J, Kirsten L, Juraskova I. An exploration of Australian psychologists' role in assessing women considering risk-reducing or contralateral prophylactic mastectomy. Breast 2017;32:105-111.

5. Wijayasinghe $N$, Duriaud HM, Kehlet $H$, Andersen KG. Ultrasound Guided Intercostobrachial Nerve Blockade in Patients with Persistent Pain after Breast Cancer Surgery: A Pilot Study. Pain Physician 2016;19:E309-E318.

6. Caputo JB, Campos SS, Pereira SM, Castelo PM, Gavião MB, Marques LS. Masticatory performance and taste perception in patients submitted to cancer treatment. J Oral Rehabil 2012;39:905-913.

7. Parsa Yekta Z, Sadeghian F, Taghavi Larijani T, Mehran A. The Comparison of Two Types of Relaxation Techniques on Postoperative State Anxiety in Candidates for The Mastectomy Surgery: A Randomized Controlled Clinical Trial. Int J Community Based Nurs Midwifery 2017;5:61-69.

8. Palma MR, Vanderlei LC, Ribeiro FE, Mantovani AM, Christofaro DG, Fregonesi CE. The relationship between post-operative time and cardiac autonomic modulation in breast cancer survivors. Int J Cardiol 2016;224:360-365
9. Shamley D, Lascurain-Aguirrebeña I, Oskrochi R. Clinical anatomy of the shoulder after treatment for breast cancer. Clin Anat 2014;27:467477.

10. Araújo Neto EA, Alves BCA, Gehrke FS, Azzalis LA, Junqueira VCB, Sousa LVA. Quality of Life of Post-Mastectomy Women Living in a Semi-Arid Region of Brazil. Int J Environ Res Public Health 2017;14:pii: E601.

11. Boudreau SA, Falla D. Chronic neck pain alters muscle activation patterns to sudden movements. Exp Brain Res 2014;232:2011-2020.

12. Sacchini V, Luini A, Tana S, Lozza L, Galimberti V, Merson M. Quantitative and qualitative cosmetic evaluation after conservative treatment for breast cancer. Eur J Cancer 1991;27:1395-1400.

13. Taylor R, Jayasinghe UW, Koelmeyer L, Ung 0, Boyages J. Reliability and validity of arm volume measurements for assessment of lymphedema. Phys Ther 2006; 86:205-214.

14. Matsudo VK, Matsudo SM, Araújo TL, Andrade DR, Oliveira LC, Hallal PC. Time trends in physical activity in the state of São Paulo, Brazil: 2002-2008. Med Sci Sports Exerc 2010;42:2231-2236.

15. Siéssere $S$, Lima NA, Semprini M, de Sousa LG, Issa JPM, Monteiro SAC, Regalo $\mathrm{SCH}$. Masticatory process in individuals with maxillary and mandibular osteoporosis: electromyographic analysis. Osteoporos Int 2009;20:1847-1851.

16. Palinkas $M$, Cecilio $F A$, Siéssere $S$, Borges Tde $F$, de Carvalho $C A$, Semprini M. Aging of masticatory efficiency in healthy subjects: electromyographic analysis--Part 2. Acta Odontol Latinoam 2013;26:161-166.

17. Hojan K, Manikowska F, Chen BP, Lin CC. The influence of an external breast prosthesis on the posture of women after mastectomy. J Back Musculoskelet Rehabil 2016;29:337-342.

18. Carvalho-Oliveira $M$, Salles $C$, Terse $R$, D'Oliveira $A$ Júnior, et al. Association between severe asthma and changes in the stomatognathic system. J Bras Pneumol 2016;42:423-428.

19. Douglas CR, Avoglio JL, de Oliveira H. Stomatognathic adaptive motor syndrome is the correct diagnosis for temporomandibular disorders. Med Hypotheses 2010;74:710-718.

20. Eriksson $\mathrm{PO}$, Häggman-Henrikson $\mathrm{B}$, Zafar $\mathrm{H}$. Jaw-neck dysfunction in whiplash-associated disorders. Arch Oral Biol 2007;52:404-408.

21. Palinkas M, Bataglion $C$, de Luca Canto G, Machado Camolezi N, Theodoro GT, Siéssere S. Impact of sleep bruxism on masseter and temporalis muscles and bite force. Cranio 2016;34:309-315.

22. Cecílio FA, Regalo SC, Palinkas M, Issa JP, Siéssere $S$, Hallak JE. Ageing and surface EMG activity patterns of masticatory muscles. J Oral Rehabil 2010;37:248-255.

23. Roggia B, Santos VA Filha, Correa B, Rossi ÂG. Posture and body balance of schoolchildren aged 8 to 12 years with and without oral breathing. Codas 2016;28:395-402

24. Zhang P, Li CZ, Wu CT, Jiao GM, Yan F, Zhu HC. Comparison of immediate breast reconstruction after mastectomy and mastectomy alone for breast cancer: A meta-analysis. Eur J Surg Oncol 2017;43:285-293.

25. Dante AMM, Santos CMD, Palinkas M, Lellis JBM, Siessere $S$, Semprini M. Effect of radiation on the performance of the stomatognathic system - a pilot study. J Dent Oral Disord Ther 2014; 2:1-5.

26. Mochizuki H, Tashiro M, Kano M, Sakurada Y, Itoh M, Yanai K. Imaging of central itch modulation in the human brain using positron emission tomography. Pain 2003;105:339-346.

27. Kiliaridis S, Georgiakaki I, Katsaros C. Masseter muscle thickness and maxillary dental arch width. Eur J Orthod 2003;25:259-263.

28. Klassen O, Schmidt ME, Ulrich CM, Schneeweiss A, Potthoff K, Steindorf $K$. Muscle strength in breast cancer patients receiving different treatment regimes. J Cachexia Sarcopenia Muscle 2016:1-12.

29. Atanes Mendes Peres AC, Dias de Oliveira Latorre MD, Yugo Maesaka J, Filassi JR, Chada Baracat E, Alves Gonçalves Ferreira E. Body posture after mastectomy: comparison between immediate breast reconstruction versus mastectomy alone. Physiother Res Int 2017;22:e1642 Epu. 